\title{
Sex ratio and dynamic behavior in populations of the exotic blowfly Chrysomya albiceps (Diptera, Calliphoridae)
}

\author{
Serra, H. ${ }^{\mathrm{a}}$, Godoy, WAC. ${ }^{\mathrm{a} *}$,Von Zuben, FJ. ${ }^{\mathrm{b}}$, Von Zuben, CJ. ${ }^{\mathrm{c}}$ and Reis, SF. ${ }^{\mathrm{d}}$ \\ ${ }^{a}$ Departamento de Parasitologia, Instituto de Biociências, Universidade Estadual Paulista - UNESP, \\ Rubião Jr., CEP 18618-000, Botucatu, SP, Brazil

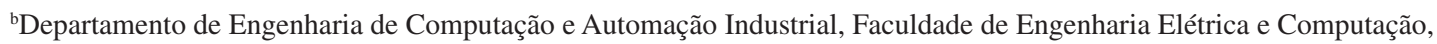 \\ Universidade Estadual de Campinas - UNICAMP, Campinas, SP, Brazil \\ 'Departamento de Zoologia, Instituto de Biociências, Universidade Estadual Paulista - UNESP, Rio Claro, SP, Brazil \\ ${ }^{d}$ Departamento de Parasitologia, Instituto de Biologia, Universidade Estadual de Campinas - UNICAMP, \\ Campinas, SP, Brazil \\ *e-mail: wgodoy@ibb.unesp.br
}

Received May 11, 2005 - Accepted July 1, 2005 - Distributed May 31, 2007

(With 1 figure)

\begin{abstract}
Sex ratio is an essential component of life history to be considered in population growth. Chrysomya albiceps is a blowfly species with a naturally biased sex ratio. In this study, we evaluated the impact of changes in sex ratio on the dynamic behavior of $C$. albiceps using a density-dependent mathematical model that incorporated demographic parameters such as survival and fecundity. These parameters were obtained by exponential regression, with survival and fecundity being estimated experimentally as a function of larval density. Bifurcation diagram of the results indicated the evolution of stable equilibrium points as a function of sex ratio. A continually increasing sex ratio yielded a hierarchy of bifurcating stable equilibrium points that evolved into a chaotic regime. The demographic parameters obtained by exponential regression were also changed to maximum and minimum values in order to analyze their influence on dynamic behavior with sex ratio being considered as an independent variable. Bifurcations with periodicity windows between chaos regimes were also found.
\end{abstract}

Keywords: density-dependent model, population dynamics, sex ratio.

\section{Razão sexual e comportamento dinâmico em populações da espécie de mosca varejeira exótica Chrysomya albiceps (Diptera, Calliphoridae)}

\begin{abstract}
Resumo
A razão sexual é um componente essencial da biologia de organismos a ser considerado em crescimento populacional. Chrysomya albiceps é uma espécie de mosca varejeira que exibe um desvio na razão sexual em relação à proporção 1:1. Neste estudo avaliamos o impacto de alterações na razão sexual sobre o comportamento dinâmico de $C$. albiceps utilizando um modelo matemático dependente da densidade que incorpora parâmetros demográficos como sobrevivência e fecundidade. Os parâmetros foram obtidos por regressão exponencial, com sobrevivência e fecundidade sendo estimadas experimentalmente em função da densidade larval. O diagrama de bifurcação gerado pelos resultados indicou a evolução de pontos de equilíbrio estável em função da razão sexual. A sucessão contínua dos valores da razão sexual resultou em uma hierarquia de pontos de equilíbrio estável produzida por bifurcações, resultando em regime caótico. Os parâmetros demográficos obtidos por regressão exponencial foram também mudados para valores máximos e mínimos, a fim de analisar a influência deles sobre o comportamento dinâmico da espécie, tendo a razão sexual como variável independente. Bifurcações com janelas de periodicidade intercaladas com o regime caótico também foram encontradas.
\end{abstract}

Palavras-chave: modelo de dependência da densidade, dinâmica populacional, razão sexual. 


\section{Introduction}

In recent years there has been frequent the use of population theory, with emphasis on density-dependent mathematical models, to investigate temporally biological populations, and the demographic aspects of persistence in population dynamics (Costantino et al., 1995; Godoy et al.; 2001, Cushing et al., 2003). Studies of population ecology have been characterized by extensive debate about the role of density-dependent processes in determining the population dynamics of natural populations (Turchin, 1990; Ray and Hastings, 1996).

Density dependence is probably one of the factors responsible for establishing patterns of intraspecific competition, such as scramble and interference (De Jong, 1976). In holometabolic insects, in which development involves discrete larval and adult phases (Chapman, 1982; Mueller, 1988), the type of competition to which immatures are subjected may determine the viability and fecundity of the resulting adults. Viability and fecundity quantitatively and qualitatively influence the dynamic behavior (population fluctuation pattern), of the population since the steady-state depends on the competition level for food experienced by the population (Edelstein-Keshet, 1988; Godoy et. al., 1993).

Several mathematical models have been used to investigate population dynamics in insects (Hassell, et al.,1976; Mueller, 1986, 1988; Dennis et al., 1995). However, there are specific and important mechanisms for blowfly populations, which should be considered in discrete models, such as delayed and function density dependence. A mathematical model developed by Prout and McChesney (1985) has frequently been used to investigate the dynamics of fly populations since it focuses on this point. This model was initially developed to investigate the population dynamics of Drosophila melanogaster (Prout and McChesney, 1985) but was subsequently used to investigate the population dynamics of blowflies (see Godoy et al. 1997; Reis et al.1996, Godoy et al. 2001). The application of this model to blowfly experimental populations revealed a two point limit cycle for Chrysomya megacephala, Chrysomya putoria and Chrysomya albiceps (Godoy et al. 1993, 2001), three species introduced into Brazil about 30 years ago (Guimarães et al.1978, 1979). In contrast, a stable equilibrium has been observed in Cochliomyia macellaria and Lucilia eximia (Reis et al. 1996; Silva et al. 2003), both of which are native species to the Americas (Guimarães et al. 1978, 1979).

Godoy et al. (1996) investigated the sensitivity of fecundity and survival in C. megacephala, C. putoria, and $C$. macellaria using the Prout and McChesney model and found that fecundity was the most sensitive parameter for detecting variations in population size and dynamics. When set to larger values, the dynamic behavior changed from periodic cycles to chaos (Godoy et al.1996, 2001). A spatial dimension introduced into the Prout and McChesney model by using the Laplacian operator (Solé et al.1992) indicated that migration be- tween local populations changed the global dynamic behavior from a two-point limit cycle to stable equilibrium (Godoy et al.,1997, 2001).

Among the parameters and processes inherent to the Prout and McChesney equation, the sex ratio is an essential component to be considered when assessing the population growth rate. The sex ratio is also an important additional factor in studies that analyze competitive differences (Nunney, 1983). Blowflies usually have a 1:1 sex ratio, however, $C$. albiceps is a bisexual species, in which the females can reproduce themselves monogenetically. In some generations, males may also be produced (Queiroz et al., 1996). This behavior of C. albiceps indicates the need for investigations into the sex ratio in order improve our understanding of population dynamics and demography of this species. Sex ratio has important implications for population growth since the number of females at a given time has a significant effect on the composition of the next generation (Queiroz et al.,1996; Brown and Keller 2000). In this work, we used the Prout and McChesney model to investigate this aspect in the biology of $C$. albiceps. Specifically, we investigated the theoretical variation in the dynamic behavior of $C$. albiceps as a function of changes in sex ratio, fecundity and survival.

\section{Materials and Methods}

The mathematical model developed by Prout and McChesney (1985) considers that the population size at generation $n_{t+1}$ depends on fecundity $(F)$ and survival $(S)$, which are functions of the larval density at $n_{t}$. The firstorder difference equation may thus be written as:

$n_{t+1}=S_{r} F\left(n_{t}\right) S\left(n_{t}\right) n_{t}$

where $\mathrm{S}_{r}$ is the sex ratio. In the Prout and McChesney study, $S_{r}$ was $1 / 2$, indicating that $50 \%$ of the population consisted of females.

In this model, fecundity and survival are estimated using an exponential regression written as $F\left(n_{t}\right)=F^{*} e^{-f n_{t}}$ for fecundity and $S\left(n_{t}\right)=S^{*} e^{-s n_{t}}$ for survival. $F^{*}$ and $S^{*}$ are regression intercepts representing theoretical values of maximum fecundity and survival, respectively, and $f$ and $s$ are regression slopes which estimate the rates of fecundity and survival variations. The exponential functions can be explicitly represented in Equation 1, leading to:

$n_{t+1}=S_{r} F^{*} S^{*} \mathrm{e}^{-(f+s) n_{t}} n_{t}$

Using Matlab 5.0 (Hanselman and Littlefield, 1997), simulations were run based on bifurcation theory (May and Oster 1976) with $S_{r}$ as the independent variable on the $x$ axis. The remaining parameters in Equation 2 were defined according to data obtained from experimental populations of $C$. albiceps (Godoy et al., 2001), as shown in Table 1. Survival and fecundity, estimated in experimental populations of blowflies under larval competition for food (Table 1), were used as demographic 
parameters in the Prout and McChesney model, based on values obtained by regression analysis (Table 2).

Thus, laboratory populations of $C$. albiceps were founded from specimens collected from the campus of the Universidade Estadual Paulista, Botucatu, in the state of São Paulo, Brazil. Exploitative intraspecific competition among immatures of $C$. albiceps, which is known to occur under natural conditions, was established in the laboratory by setting up six larval densities, 100, $200,400,600,800$ and 1,000 larvae per vial $(7.2 \mathrm{~cm}$ by $13.8 \mathrm{~cm}$ ), with two replicates for each density. Fecundity was measured by counting the number of eggs per female and expressed as average daily egg output, based on the length of the gonotrophic cycle at $25{ }^{\circ} \mathrm{C}$ (Linhares, 1988). Survival was estimated as the number of adults emerging from each vial.

Exponential regressions for fecundity and survival as functions of increasing larval density were fitted to the data for C. albiceps using PROC REG (SAS Institute, 1988). We chose an exponential regression because it provided a better fit than linear and hyperbolic regressions to the data for C. albiceps (Godoy et al., 2001). The exponential regression analysis is shown in Table 2 . An initial population size of 100 individuals was considered and the sex ratio was varied above and below 0.5 , which corresponded to different numbers of females for each simulation.

The maximum and minimum fecundity and survival obtained experimentally were also used in the simulations. All possible combinations between the experimental (Table 1) and theoretical (Table 2) fecundity and

Table 1. Mean daily fecundity and survival for six larval densities of Chrysomya albiceps

\begin{tabular}{rrrrrc}
\hline Densities & \multicolumn{2}{c}{$\begin{array}{c}\text { Fecundity } \\
\text { (number of eggs) }\end{array}$} & & \multicolumn{2}{c}{ Survival (\%) } \\
\cline { 2 - 3 } \cline { 5 - 6 } & $\mathbf{N}$ & $\overline{\boldsymbol{x}} \pm$ Sd & & $\mathbf{N}$ & $\overline{\boldsymbol{x}} \pm \mathbf{S d}$ \\
\hline 100 & 25 & $26.46^{*} \pm 4.13$ & & 2 & $54^{*} \pm 8.5$ \\
200 & 54 & $21.02 \pm 2.96$ & & 2 & $34 \pm 9.5$ \\
400 & 29 & $19.24 \pm 2.97$ & & 2 & $12 \pm 11.4$ \\
600 & 17 & $15.91 \pm 3.15$ & & 2 & $7.2 \pm 6.8$ \\
800 & 22 & $13.63 \pm 2.87$ & & 2 & $6.9 \pm 2.4$ \\
1000 & 10 & $8.57^{*} \pm 2.43$ & & 2 & $2 * \pm 0$ \\
\hline
\end{tabular}

$x=$ mean fecundity and survival, $\mathrm{N}=$ sample size;

* Maximum and minimum fecundity and survival obtained experimentally; and $\mathrm{N}=$ Number of females dissected to obtain fecundity and number of experimental populations used to estimate survival. survival were used in the simulations. These included: fecundity and survival obtained by regression, minimum fecundity and maximum survival, minimum fecundity and minimum survival, minimum fecundity and survival obtained by regression, fecundity obtained by regression and minimum survival, fecundity obtained by regression and maximum survival, maximum fecundity and survival, maximum fecundity and minimum survival and maximum fecundity and survival obtained by regression.

We also examined the effect of variations considering $100 \%$ of survival (arbitrary) and fecundity obtained by regression, and arbitrary fecundity (40) and survival obtained by regression. In addition, we investigated the effect of variations considering all combinations between arbitrary maximum and minimum fecundity, survival and values obtained by regression (Table 3). We point out that the upper limit of $100 \%$ of survival and 40 eggs used in our simulations does not match exactly the values observed for this species, since the maximum number of eggs can be either smaller or larger and survival smaller, depending upon the level of competition experienced by the larvae (Ullyett, 1950; Von Zuben et al., 1993). However, these values are compatible with values found in natural populations of blowflies (Ullyett, 1950, Godoy et al., 1996).

\section{Results}

A bifurcation diagram showed that increasing the sex ratio produced qualitative changes in the dynamics of C. albiceps (Figure 1), which suggested that increasing the number of females made the system more complex. Progressively increasing the sex ratio yielded a hierarchy of bifurcating stable equilibrium points that evolved to a chaotic regime. The results were classified in five scenarios, which describe different dynamic behaviors associated to combination of parameters.

We also investigated the dynamic behavior of C. albiceps with maximum and minimum fecundity and survival experimentally obtained and arbitrarily applied, combined with theoretical values obtained from regression analysis. In this case, the sex ratio was fixed at 0.5. The results indicated that it is absolutely equivalent to a change of sex ratio at interval $[0.0909,0.9090]$ using the values for $F^{*}$ and $S^{*}$ obtained by regression. The effect of variations between the maximum (1) and minimum (0.5) survival, compatible with values from experimental and natural populations of blowflies (Godoy et al.,1997, 2001), was also equivalent to the changing sex ratio over

Table 2. Regression analysis parameters for fecundity and survival as a function of larval density

\begin{tabular}{lcc}
\hline & Fecundity $\left(F^{*}\right)$ & Survival $\left(S^{*}\right)$ \\
\hline Maximum (Fecundity and Survival) & 27.11 & 0.565 \\
Regression coefficient $(f$ and $s$ ) & $1 \times 10^{-3}$ & $3 \times 10^{-3}$ \\
t value & $18.36^{\circ}$ & 5.48 \\
$r^{2}$ & 0.68 & 0.75 \\
F (Anova) & 337 & 30 \\
\hline
\end{tabular}

$\cdot \mathrm{P}<0.001$ 
Table 3. Results obtained for five scenarios (Figure 1) showing the effect of sex ratio with different parameter values.

\begin{tabular}{|c|c|c|c|}
\hline \multirow{2}{*}{$\begin{array}{c}\text { Combination of } \\
\text { parameters }\end{array}$} & \multicolumn{2}{|c|}{ Values } & \multirow[t]{2}{*}{ Scenario } \\
\hline & Fecundity & Survival & \\
\hline $\mathrm{F}_{\max }$ e $\mathrm{S}_{\text {min }}$ & 26.46 & 0.02 & 1 \\
\hline $\mathrm{F}_{\min }$ e $\mathrm{S}_{\max }$ & 8.57 & 0.54 & 1 \\
\hline $\mathrm{F}_{\min }$ e $\mathrm{S}_{\min }$ & 8.57 & 0.02 & 1 \\
\hline $\mathrm{F}_{\min }$ e $\mathrm{S}_{\mathrm{reg}}$ & 8.57 & 0.56 & 1 \\
\hline $\mathrm{F}_{\mathrm{reg}}$ e $\mathrm{S}_{\min }$ & 27.11 & 0.02 & 1 \\
\hline $\mathrm{F}_{\text {min arb }}$ e $S_{\text {min arb }}$ & 4 & 0.01 & 1 \\
\hline $\mathrm{F}_{\text {max arb }}$ e $S_{\text {min arb }}$ & 40 & 0.01 & 1 \\
\hline $\mathrm{F}_{\text {min arb }}$ e $S_{\text {max arb }}$ & 4 & 1 & 1 \\
\hline $\mathrm{F}_{\text {min arb }}$ e $\mathrm{S}_{\mathrm{reg}}$ & 4 & 0.56 & 1 \\
\hline $\mathrm{F}_{\mathrm{reg}}$ e $\mathrm{S}_{\min \text { arb }}$ & 27.11 & 0.01 & 1 \\
\hline $\mathrm{F}_{\max }$ e $\mathrm{S}_{\max }$ & 26.46 & 0.54 & 2 \\
\hline $\mathrm{F}_{\mathrm{reg}}$ e $\mathrm{S}_{\max }$ & 27.11 & 0.54 & 3 \\
\hline $\mathrm{F}_{\mathrm{reg}}$ e $\mathrm{S}_{\mathrm{reg}}$ & 27.11 & 0.56 & 4 \\
\hline $\mathrm{F}_{\max }$ e $\mathrm{S}_{\mathrm{reg}}$ & 26.46 & 0.56 & 4 \\
\hline $\mathrm{F}_{\text {max arb }}$ e $\mathrm{S}_{\mathrm{reg}}$ & 40 & 0.56 & 4 \\
\hline $\mathrm{F}_{\max a \mathrm{arb}}$ e $\mathrm{S}_{\max a r b}$ & 40 & 1 & 5 \\
\hline $\mathrm{F}_{\mathrm{reg}}$ e $\mathrm{S}_{\text {max arb }}$ & 27.11 & 1 & 5 \\
\hline \multicolumn{4}{|c|}{$\begin{array}{l}\mathrm{F}_{\max }=\text { maximum fecundity; } \mathrm{F}_{\min }=\text { minimum fecundity, } \\
\mathrm{F}_{\text {reg }}=\text { fecundity obtained by regression; } \mathrm{F}_{\text {max arb }}=\text { arbitrary } \\
\text { maximum fecundity; } \mathrm{F}_{\text {min arb }}=\text { arbitrary minimum fecun- } \\
\text { dity. } \mathrm{S}_{\max }=\text { maximum survival; } \mathrm{S}_{\min }=\text { minimum survival; } \\
\mathrm{S}_{\text {reg }}=\text { survival obtained by regression; } \mathrm{S}_{\max \text { arb }}=\text { arbitrary } \\
\text { maximum survival; } \mathrm{S}_{\text {min arb }} \text { - arbitrary minimum survival. }\end{array}$} \\
\hline
\end{tabular}

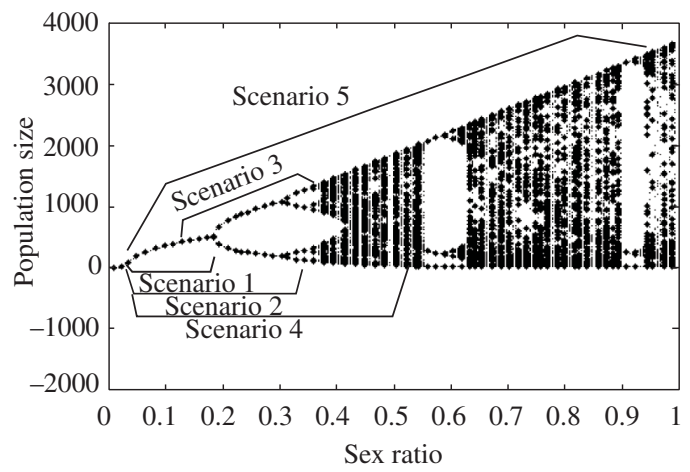

Figure 1. Bifurcation diagram for stable population sizes as a function of variation in the sex ratio for Chrysomya albiceps.

the interval $[0.3333,0.6667]$ using the $F^{*}$ and $S^{*}$ obtained by regression. Therefore, by studying only the effect of variations in the sex ratio over the interval $[0,1]$, we found that the parametric spectrum analyzed was larger than that investigated when $F^{*}$ and $S^{*}$ were varied alone in previous studies.
One point stable equilibrium was found when $F$ was set to the maximum value (26.46) and $S$ to the minimum (0.02) (Table 1, Figure 1). The same result was observed setting $F$ to the minimum value (8.57) and $S$ to the maximum value (0.54) (Table 3, Figure 1, Scenario 1). When $F$ and $S$ were set to minimum values, 8.57 and 0.02 respectively, a stable equilibrium was also obtained. This dynamic behavior was also found by setting $F$ to the minimum value (8.57) and maintaining the theoretical $S$ value $(0.56)$ obtained by regression (Table 3 , Figure 1 , Scenario 1). When $F$ was maintained at the theoretical value (27.11) and $S$ set to the minimum (0.02) the result was also a stable equilibrium (Table 3 and Figure 1).

Combining arbitrary minimum fecundity (4) with arbitrary minimum survival $(0.01)$ and arbitrary maximum fecundity (40) with arbitrary minimum survival $(0.01)$, the result was also a stable equilibrium (Table 3, Figure 1, Scenario 1). This result was also found when arbitrary minimum fecundity (4) was combined with arbitrary maximum survival (1), arbitrary minimum fecundity (4) was combined with survival obtained by regression (0.56) and fecundity obtained by regression (27.11) was combined with arbitrary minimum survival (0.01) (Table 3, Figure 1, Scenario 1). However, with maximum $F$ (26.46) and $S$ (0.54), the diagram showed bifurcation with two-points splitting into four-points (Table 3, Figure 1, Scenario 2).

Setting $F$ to the theoretical value obtained from regression (27.11) and $S$ to the maximum value experimentally obtained (0.54) the bifurcation diagram showed one-point stable equilibrium, two, four, eight and sixteen-point limit cycles (Table 3, Figure 1, Scenario 3). Applying values of fecundity and survival obtained by regression, 27.11 and 0.56 respectively, the simulation revealed a cascade of bifurcations with stable equilibrium, limit cycles and chaos (Table 3, Figure 1, Scenario 4). The same scenario was obtained when maximum fecundity (26.46) was combined with survival obtained by regression (0.56) and arbitrary maximum fecundity (40) was combined with survival obtained by regression (0.56) (Table 3, Figure 1). Setting $F$ to 40 (arbitrary maximum fecundity), to 27.11 (value obtained by regression) and $S$ to the maximum arbitrary (1), the graph showed a cascade of bifurcations with two-cycle splitting into four-cycle, splitting into eight-cycle, and so on until reaching chaos, including two well visible periodicity windows (Table 3, Figure 1 Scenario 5).

\section{Discussion}

The birfurcation diagram obtained showed that qualitative changes in the dynamics of $C$. albiceps can be produced in response to different values of sex ratio. The dynamics of Equation 2 is similar to that described by the logistic and Ricker maps, which are employed to model density-dependent population dynamics (May and Oster, 1976), and displays the behavior of period-doubling route to chaos (Figure 1), first cited by Feigenbaum (1983). In a previous study, Godoy et al.(1996) showed 
that the transition from an asymptotic stable equilibrium to bounded oscillations occurred as a function of increasing fecundity and survival.

These authors analysed the transition of dynamic behavior in C. megacephala, C. putoria and C. macellaria and observed that the effect of survival on the dynamics of these species was much less noticeable than that of fecundity since no more than one bifurcation was obtained in the three species studied. Fecundity was found to be the most important demographic parameter in changing the dynamic behavior of experimental populations of C. megacephala, C. putoria and C. macellaria (Godoy et al.1996).

The results found in this study also indicate that populations of $C$. albiceps may exhibit different equilibria in response to different values of sex ratio, depending on the magnitude of fecundity and survival. Periodicity windows were also observed over the simulations, specially where survival was set to 1 (Scenario 5). Simple discrete-time ecological models for a species are shown to have complex transient dynamics (Cushing et al. 2003). If the density dependence is strong enough, then the time required to reach the final dynamics is usually very long, approaching thousands of generations, and there are typically very sudden changes in the form of the dynamics (Hastings and Higgins, 1994). Apparent chaos can change to cycles or vice versa (Higgins et al., 1997). Our results are consistent with observed sudden changes in the form of the dynamics of a single species and imply that transient dynamics of ecological models may be more relevant than long-term behavior (Hastings and Higgins, 1994). Transient behavior can also be an essential part of the explanation for the distribution and abundance of species and an important aspect of the coexistence of competitors (Hastings, 2004).

The stability of equilibrium has extensively been investigated in insect populations (Prout and McChesney, 1985; Costantino et al., 1995; Teixeira et al., 1998). Perhaps the most important question arising in this context is what governs the transition from a stable to an unstable equilibrium. The effects produced by the manipulation of parameter values are well known in theoretical population models (May and Oster, 1976, Edelstein-Keshet, 1988), with evidence for such changes coming from theoretical and empirical studies (Cavalieri and Koçak, 1995; Costantino et al., 1995; Godoy et al., 2001).

Experiments designed to test predictive models have shown that shifts in dynamic behavior can occur from stable equilibrium, to stable cycles and so on to aperiodic cycles in response to changes in adult mortality (Costantino et al., 1995; Godoy et al., 2001). Although these investigations have focused on steady-state, sex ratio has not yet been studied in this context. The importance of this parameter as a component of population models derives from ecological and genetic factors.

In some organisms, sex determination is governed by genes, although other factors such as temperature
(Conover and Demond, 1991) may also influence the sex ratio. In some species, sex is determined by the joint effects of temperature and sex-determining genes (Conover and Demond, 1991). Sex allocation has been investigated more intensely in social insects as a function of factors such as colony size, genetic structure, food availability, season and parental investment (Bourke, 2001; Passera et al., 2001; Hammond et al., 2002).

Butterflies show sex-role reversal caused by selfish genetic elements that distort the sex ratio towards females. Acraea encedon and A. encedana are female biased because over $90 \%$ of the females are infected with Wolbachia bacterium that is maternally inherited and kills male embryos (Jiggins et al., 2000). Offspring sex ratios tend to be more female biased in situations conducive to large offspring size than in situations producing offspring of small size (Sargent and Reid, 1999). The gypsy moth Lymantria dispar may produce only female progeny because of a certain cytoplasmic factor capable of selectively killing males in eggs, thereby differentially resulting in only female hosts (Higashiura et al., 1999).

Few mathematical models have attempted to link sex ratio with population theory. For insects, Carey (1993) has developed important theoretical approaches to investigate the sex ratio in specific ages or stages, and to assess the overall sex ratio. Although it is not known why C. albiceps has a naturally biased sex ratio, our investigation has shown the importance of this parameter for population dynamics of the species. Indeed, the Prout and McChesney model showed that sex ratio was a very sensitive parameter since small changes were sufficient to produce qualitative alterations in the behavior of the population.

The results obtained in this study are not unexpected since it is well known that changes in the parameters that govern population growth will lead to transitions from oscillatory stable states to chaotic behavior, including blowfly population analysis (May and Oster, 1976; Godoy et al., 2001). We believe that our results are more significant in the light of findings by Cavalieri and Koçak (1995), Costantino et al.(1995), Cushing et al.(2003) who demonstrated the transition from steady cycles to chaos by adjusting birth and death rates in population of the corn borer, Ostrinia nubalis and for Tribolium. These findings established the importance of variation in demographic parameters and shifts in population dynamic behavior, and these shifts also may have important implications for the rates of species extinction (Allen et al.,1993).

Allen et al.(1993) demonstrated that chaotic behavior enhances the probability of species survival if populations are spatially structured, that is, if populations within a species are linked by migration and behave effectively as metapopulations. Chrysomya albiceps, that have increased in population numbers (Souza and Linhares, 1997; Carvalho et al., 2000) do show a potential to exhibit aperiod oscillations (Godoy et al., 2001) and might, according to Allen et al. (1993) have enhanced 
rates of survival. The strong connection between shifts in dynamic equilibrium and rates of extinction and survival in spatially structured populations requires a knowledge of the effects that dispersal may have on the dynamics of C. albiceps.

Acknowledgments - Work by H.S. was supported by a fellowship from the Conselho Nacional de Desenvolvimento Científico e Tecnológico (CNPq). WACG, FJVZ, CJVZ and SFR are supported by research fellowships from CNPq. The manuscript was improved by constructive criticisms from an anonymous reviewer.

\section{References}

ALLEN, JC., SCHAEFFER, WW. and ROSKOD., 1993, Chaos reduces species extinction by amplifying local population noise. Nature, vol. 364, no. 6434, p. 229-232.

BOURKE, AFG., 2001, Reproductive skew and split sex ratios in social Hymenoptera. Evolution, vol. 55, no. 10, p. 2131-2136.

BROWN, WD. and KELLER, L., 2000, Colony sex ratios vary with queen number but not relatedness asymmetry in the ant Formica exsecta. Proc. Royal Soc. Lond., B 267, p. 1751-1757.

CAREY, JR., 1993, Applied Demography for Biologists with Special Emphasis on Insects. Oxford University Press, New York, $224 \mathrm{p}$.

CARVALHO, LML., THYSSEN, PJ., LINHARES, AX. and PALHARES, FAB., 2000, A checklist of arthropods associated with pig carrion and human corpses in Southeastern Brazil. Mem. Inst. Oswaldo Cruz, vol. 95, no. 1, p. 135-138.

CAVALIERI, LF. and KOÇAK, H., 1995, Intermittent transition between order and chaos in an insect pest population. J. Theor. Biol., vol. 175, no. 2, p. 231-234.

CHAPMAN, RF., 1982, The insects, structure and function. Harvard Univesity Press. Cambridge, 919p.

CONOVER, DO. and DEMOND, SB., 1991, Absence of temperature-dependent sex determination in northern populations of two cyprinodontid fishes. Can. J. Zool., vol. 69, p. $530-533$.

COSTANTINO, RF., CUSHING, JM., DENNIS, B. and DESHARNAIS, RA., 1995, Experimentally induced transitions in the dynamic behavior of insect populations. Nature, vol. 375, p. $227-230$.

CUSHING, JM., COSTANTINO, RF. DENNIS, B., DESHARNAIS, RA. and HENSON, SM., 2003, Chaos in ecology, experimental nonlinear dynamics. Academic Press, Amsterdam, 225p.

DE JONG, G., 1976, A model of competition for food. I. Frequency-dependent variabilities. Am. Nat. vol. 110, p. 1013-1027.

DENNIS, B., DESHARNAIS RA., CUSHING JM. and COSTANTINO RF., 1995, Nonlinear demographic dynamic dynamics: mathematical model, statistical methods and biological experiments. Ecol. Mon., vol. 65, no.3, p. 261-281.

EDELSTEIN-KESHET, L., 1988, Mathematical Models in Biology. Random House, New York, 568p.
FEIGENBAUM, MJ., 1983, Universal behavior in nonlinear systems. Physica, 7D, no.1, p. 16-39.

GODOY, WAC., REIS, SF., VON ZUBEN, CJ. and RIBEIRO, OB., 1993, Population dynamics of Chrysomya putoria (Wied.) (Dipt., Calliphoridae). J. App. Entomol., vol. 116, p. 163-169.

GODOY, WAC., VON ZUBEN, CJ., REIS, SF. and VON ZUBEN, FJ., 1996, Dynamics of experimental populations of native and introduced blowflies (Diptera: Calliphoridae): mathematical modelling and the transition from asymptotic equilibrium to bounded oscillations. Mem. Inst. Oswaldo Cruz, vol. 91 , no. 5, p. 641-648.

-, 1997, The spatial dynamics of native and introduced blowflies (Dipt., Calliphoridae). J. App. Entomol., vol. 121, p. 305-309.

GODOY, WAC., VON ZUBEN, FJ., VON ZUBEN CJ. and REIS SF., 2001, Spatio-temporal dynamics and transition from asymptotic equilibrium to bounded oscillations in Chrysomya albiceps (Diptera, Calliphoridae). Mem. Inst. Oswaldo Cruz, vol. 96 , no. 5, p. 627-634.

GUIMARÃES, JH., PRADO, AP. and BURALLI, GM., 1979, Dispersal and distribution of three newly introduced species of Chrysomya Robineau-Desvoidy in Brazil (Diptera, Calliphoridae). Revta. Bras. Entomol., vol. 23, p. 245-255.

GUIMARÃES, JH., PRADO, AP. and LINHARES, AX., 1978, Three newly introduced blowfly species in southern Brazil (Diptera: Calliphoridae). Revta. Bras. Entomol., vol. 22, p. $53-60$.

HAMMOND RL., BRUFORD, MW. and BOURKE, AFV., 2002, Ant workers selfishly bias sex ratios by manipulating female development. Proc. Royal Soc. Lond., Ser. B 269, p. $173-178$.

HANSELMAN, D. and LITTLEFIELD, B., 1997, Matlab, the language of technical computing, Version 5.0. User's Guide, The Math Works Inc. Prentice Hall, Upper Saddle River, New Jersey, $429 \mathrm{p}$.

HASSELL, M. P., LAWTON, J. and MAY, R. M., 1976, Patterns of dynamical behavior in single-species populations. J. Anim. Ecol., vol. 45, p. 471-486.

HASTINGS, A., 2004, Transients: the key to long-term ecological understanding? Tree, vol. 19, no. 1, p. 39-45.

HASTINGS, A. and HIGGINS, K., 1994, Persistence of transients in spatially structured ecological models. Science, vol. 263, p. 1133-1136.

HIGASHIURA, Y., ISHIHARA, MP. and SCHAEFER, W., 1999, Sex ratio distortion and severe inbreeding depression in the gypsy moth Lymantria dispar L-in Hokkaido, Japan. Heredity, vol. 83, p. 290-297.

HIGGINS, K., HASTINGS, A. and BOTSFORD, LW., 1997, Density dependence and age structure: nonlinear dynamics and population behavior. Am. Nat., vol. 149, p. 247-269.

JIGGINS, FM., HURST, GDD. and MAJERUS, MEN., 2000, Sex-ratio-distorting Wolbachia causes sex-role reversal in its butterfly host. Proc. Royal Soc. Lond., Ser. B. vol. 267, p. 69-73.

LINHARES, AX., 1988, The gonotrophic cycle of Chrysomya megacephala (Diptera: Calliphoridae) in the laboratory. Revta. Bras. Entomol. no. 32, p. 383-392. 
MAY, RM. and OSTER, GF., 1976, Bifurcations and dynamic complexity in simple ecological models. Am. Nat., vol. 110, p. 573-599.

MUELLER, LD., 1986, Density-dependent rates of population growth: estimation in laboratory populations. Am. Nat. vol. 128, p. 282-293.

-, 1988, Density-dependent population growth and natural selection in food limited environments: the Drosophila model. Am. Nat., vol. 132, p. 786-809.

NUNNEY, L., 1983, Sex differences in larval competition in Drosophila melanogaster. The testing of a competition model and its relevance to frequency-dependent selection. Am. Nat. vol. 21, p. 67-93.

PASSERA, L., ARON, S., VARGO, EL. and KELLER, L., 2001, Queen control of sex ratio in fire ants. Science, vol. 293, p. $1308-1310$.

PROUT, T. and McCHESNEY, F., 1985, Competition among immatures affects their adult fertility: population dynamics. Am. Nat., vol. 126, p. 521-558.

QUEIROZ, MMD., MELLO, RP. and FREIRE, NMDF., 1996, The effect of different proportions of males and females over the Chrysomyaalbiceps (Wiedemann 1819)(Diptera, Calliphoridae) biotic potential and longevity under laboratory conditions. Mem. Inst. Osw. Cruz, vol. 91, no.2, p. 243-247.

RAY, C. and HASTINGS, A.,1996, Density dependence: are we searching at the wrong spatial scale? J. Anim. Ecol., vol. 65, p. $556-566$.

REIS, SF., TEIXEIRA, MA., VON ZUBEN, FJ., GODOY, WAC. and VON ZUBEN, CJ., 1996, Theoretical dynamics of experimental populations of introduced and native blowflies (Diptera, Calliphoridae). J. Med. Entomol., vol. 33, no. 4, p. 537-544.
SARGENT, RD. and REID, ML., 1999, Unexpected offspring sex ratios in response to habitat quality in a size-dimorphic bark beetle. Can. J. Zool., vol. 77, p. 524-529.

SAS INSTITUTE.,1988, SAS/STAT User's guide, release 6.03 ed. SAS Institute, Cary, N. C.

SILVA, ICR., MANCERA, PFA. and GODOY, WAC., 2003, Population dynamics of Lucilia eximia (Diptera: Calliphoridae). J. Appl. Entomol., vol. 127, p. 2-6.

SOLÉ, RV., BASCOMPTE, J. and VALLS, J., 1992, Nonequilibrium dynamics in lattice ecosystems: chaotic stability and dissipative structures. Chaos, vol. 2, no. 3, p. 387-395.

SOUZA, AM. and LINHARES, AX., 1997, Diptera and Coleoptera of potential forensic importance in Southeastern Brazil: Relative abundance and seasonality. Med. Vet. Entomol., vol. 11, no. 1, p. 8-12.

TEIXEIRA, MA., VON ZUBEN, FJ., GODOY, WAC., VON ZUBEN, CJ. and REIS, S. F., 1998, Delayed density dependence at the immature stage in insects and the dynamic behavior of nonlinear difference equations. Ciênc. Cult., vol. 50, no. 4, p. $268-272$.

TURCHIN, P., 1990, Rarity of density dependence or population regulation with lags? Nature, vol. 344, p. 660-663.

ULLYETT, GC., 1950, Competition for food and allied phenomena in sheep-blowfly populations. Phil.Trans. Royal Soc. Lond. Ser. B Biol. Sci., vol. 234, p. 77-174.

VON ZUBEN, CJ., REIS, SF., DO VAL, JB. R., GODOY, WAC. and RIBEIRO, OB., 1993, Dynamics of a mathematical model of Chrysomya megacephala (Diptera: Calliphoridae). J. Med. Entomol., vol. 30, no. 2, p. 443-448. 
